\title{
Prospective study of alcohol drinking patterns and coronary heart disease in women and men
}

Janne Tolstrup, Majken K Jensen, Anne Tjønneland, Kim Overvad, Kenneth J Mukamal, Morten Grønbæk

\begin{abstract}
Objective To determine the association between alcohol drinking patterns and risk of coronary heart disease in women and men.

Design Population based cohort study.

Setting Denmark, 1993-2002.

Participants 28448 women and 25052 men aged 50-65 years, who were free of cardiovascular disease at entry to the study.

Main outcome measures Incidence of coronary heart disease occurring during a median follow-up period of 5.7 years.

Results 749 and 1283 coronary heart disease events occurred among women and men. Women who drank alcohol on at least one day a week had a lower risk of coronary heart disease than women who drank alcohol on less than one day a week. Little difference was found, however, between drinking frequency: one day a week (hazard ratio $0.64,95 \%$ confidence interval 0.51 to 0.81$), 2-4$ days a week $(0.63,0.52$ to 0.77$)$, five or six days a week $(0.79,0.61$ to 1.03$)$, and seven days a week $(0.65,0.51$ to 0.84). For men an inverse association was found between drinking frequency and risk of coronary heart disease across the entire range of drinking frequencies. The lowest risk was observed among men who drank daily $(0.59,0.48$ to 0.71$)$ compared with men who drank alcohol on less than one day a week.

Conclusions Among women alcohol intake may be the primary determinant of the inverse association between drinking alcohol and risk of coronary heart disease whereas among men, drinking frequency, not alcohol intake, seems more important.
\end{abstract}

\section{Introduction}

Prospective studies have consistently reported a lower risk of coronary heart disease among consumers of moderate alcohol compared with abstainers. ${ }^{1} \mathrm{~A}$ few studies have investigated this association by also including various measures of alcohol drinking patterns. Results consistently imply that the pattern of drinking is important and that steady drinking is more beneficial than drinking in binges. ${ }^{2-6}$ In a recent such study among men it was suggested that drinking frequency is the primary determinant of the inverse association between alcohol intake and coronary heart disease, and that alcohol intake is of minor importance. ${ }^{6}$ Some issues still warrant consideration however; most importantly, data on the importance of drinking patterns among women are limited and results obtained among men may not apply to women for different reasons. Firstly, sex differences in alcohol pharmacokinetics have been reported, suggesting that men have more efficient first pass metabolisms than women whereas women may eliminate alcohol faster than men. ${ }^{7}$ Secondly, oestrogen has beneficial effects on the cardiovascular system, and studies have suggested that alcohol increases oestrogen levels. ${ }^{8}$

We determined the association between alcohol drinking patterns and coronary heart disease among men and women participating in a population based cohort study consisting of middle aged Danish citizens.

\section{Methods}

From December 1993 to May 1997, 160725 Danish men and women were invited to participate in the diet, cancer, and health study. ${ }^{9}$ Eligible cohort members were born in Denmark and had no previous cancers. Overall, 27178 men and 29875 women agreed to participate (response rate 35\%). A detailed food frequency questionnaire consisting of 192 items was enclosed with the invitation. ${ }^{10} 11$ This questionnaire was checked by an interviewer during a clinic visit, when another questionnaire concerning lifestyle and background factors was completed.

In the food frequency questionnaire alcohol intake was reported as the average amount over the preceding year. Total intake was calculated and converted into number of standard drinks, defined as containing $12 \mathrm{~g}$ of ethanol. Drinking frequency was reported in the background questionnaire in predefined categories (never, less than once a month, 1-3 times monthly, once a week, 2-4 times weekly, 5 or 6 times weekly, and daily). We defined abstainers as those who reported no alcohol intake (amount) and no drinking occasions (frequency). To increase homogeneity among abstainers we excluded 786 people who reported no amount but a frequency greater than zero (or vice versa). We also excluded people with missing information $(\mathrm{n}=303)$ or with conflicting answers on amount and frequency of alcohol intake ( $\mathrm{n}=97)$. In all, 53500 people were eligible for this study.

\section{Follow-up}

We obtained information on coronary heart disease from the Danish Hospital Discharge Register ${ }^{12}$ and from the Danish Register of Causes of Death, ${ }^{13}$ where, respectively, all admissions to hospital for somatic conditions and causes of death in Denmark are registered. The hospital register is updated to 2002, whereas the causes of death register, which contains information on fatal incidents of coronary heart disease, is updated to 2000. In the period that was covered by both registers, the causes of death register contributed information on only $8 \%$ of cases. Hence we decided to end follow-up at January 2002, being aware that information on some fatal cases would be missed from January 2000 to January 2002. 
In both registers diagnoses are classified according to the international classification of diseases, eighth and 10th revisions (codes for coronary heart disease: ICD-8, 410-414 and ICD-10, I20-I25). We obtained vital status of the participants from the National Central Person Register. To minimise the risk of including preclinical cases, we excluded 2367 participants who, at baseline, were registered with any cardiovascular disease (ischaemic stroke, arrhythmias, congestive heart failure, or peripheral arteriosclerosis).

We observed participants from enrolment until date of coronary heart event $(n=2113)$, death from other causes $(n=1483)$, emigration $(n=183)$, loss to follow-up $(n=3)$, or 1 January 2002 , whichever came first.

\section{Statistical analysis}

We calculated risk estimates using Cox proportional hazard regression models, with delayed entry implemented (SAS/STAT program software). To ensure maximal adjustment for confounding by age we used age as the time axis. We adjusted the risk estimates for known risk factors for coronary heart disease: length of school education (short, $\leq 7$ years; medium, 8 - 10 years; long, $\geq 11$ years); smoking (never; former; current, 1-14, 15-24, or $>24 \mathrm{~g}$ of tobacco/day); physical activity during leisure time (dummy variables were coded for each of the following activities: sports, walking, bicycling, housework, gardening, do it yourself); body mass index (modelled as linear splines, with knots set at 20 and 25); total intake of fruit, vegetables, and fish; and percentage of total energy intake from saturated fat (all as continuous variables). We calculated the total intake of different dietary factors using the software program Food Calc (release 1.3, www.FoodCalc.dk). Using linear splines with knots set at quintiles of the covariate in question we evaluated the assumed linearity of quantitative risk factors. We tested assumptions of the proportional hazards model but detected no violations.

To test for linear trends we treated the median value within categories continuously. We did not include abstainers when testing for trend because they may have different trait and health status than people who consume alcohol lightly to moderately, ${ }^{14}$ causing a spuriously high relative risk in this category.

To examine the magnitude of rank correlation between drinking frequency and amount of alcohol, we calculated Spearman's correlation coefficient. We tested the interaction between sex and drinking frequency using a nested log likelihood test where we compared a model containing the variables as single terms with a model including the interaction terms.

To tackle the external validity of our results, we compared the observed with the expected number of cases, on the basis of age and calendar year specific incidence rates in the general Danish population. These were calculated using nationwide information from the Danish Hospital Discharge Register. ${ }^{12}$

\section{Results}

Overall, 53500 people were eligible for our study: 28448 women and 25052 men. Women consumed a median of 5.5 alcoholic drinks a week (fifth to 95th centiles, 0.3-24) and men 11.3 (1.1-47). Drinking frequency was highly correlated with amount of alcohol intake among both women and men $(r=0.86$ and $r=0.78$ ).

Infrequent drinkers (less than one day a week) and daily drinkers (daily) were more likely to be smokers, to have a lower intake of fruit and vegetables, and to be less educated than participants in the in between drinking frequencies (table 1). Body mass index was inversely associated with drinking frequency and frequent drinkers had the lowest body mass index. These trends were the same for both sexes. Generally, fewer women than men were current and heavy smokers ( $>25 \mathrm{~g}$ of tobacco daily) and women had more hours of physical activity a week and consumed more fruit and vegetables.

During follow-up (median 5.7 years, range 0.01-8.10) 749 women and 1283 men developed coronary heart disease. Information on 1933 of these cases came from the Danish Hospital Discharge Register. Based on incidence rates from the general population the expected number of cases from this register was 716 women ( 737 observed) and 1217 men (1196 observed). The observed number did not differ significantly from the expected $(\mathrm{P}>0.10)$.

Amount of alcohol intake was inversely associated with coronary heart disease among women and men (figure).

Among women, drinking on at least one day a week was associated with a lower risk of coronary heart disease than drinking more rarely than one day a week (table 2). Hazard ratios were similar for drinking on one day a week $(0.64,95 \%$ confidence interval 0.51 to 0.81$), 2-4$ days a week $(0.63,0.52$ to 0.77$)$, five or six days a week $(0.79,0.61$ to 1.03$)$, and seven days a week $(0.65$, 0.51 to 0.84$)$. A test for trend not including women that were drinking more rarely than one day a week was statistically insignificant $(\mathrm{P}=0.49)$.

Among men, drinking frequency was inversely associated with risk of coronary heart disease over the whole range of drinking frequencies (table 2). Hazard ratios were 0.93 (0.75 to 1.16) for drinking on one day a week, 0.78 (0.66 to 0.94 ) for $2-4$ days a week, 0.71 ( 0.57 to 0.87 ) for five or six days a week, and $0.59(0.48$ to 0.71$)$ for seven days a week ( $\mathrm{P}$ for trend $<0.0001)$. The test for linear trend remained statistically significant after excluding men drinking more rarely than on one day a week $(\mathrm{P}<0.0001)$.

A statistically significant interaction was found between sex and drinking frequency on the risk of coronary heart disease $(\mathrm{P}=0.02)$.

Table 3 lists the hazard ratios of coronary heart disease for different combinations of alcohol amount and drinking frequency. Within similar categories of drinking frequency, women drinking the largest amounts generally had the lowest risk. For example, among women drinking on 2-4 days a week the hazard ratio was 0.78 ( 0.63 to 0.97 ) for $1-6$ drinks a week, 0.74 ( 0.57 to 0.96$)$ for $7-13$ drinks a week, and 0.27 (0.13 to 0.58 ) for 14 or more drinks a week ( $\mathrm{P}$ for trend $<0.0001)$. For men, hazard ratios were generally lowest for the most frequent intake within similar categories of amount (table 3). For example, among men drinking on average 7-13 drinks a week, hazard ratios of coronary heart disease were 0.89 (0.62 to 1.29) for drinking alcohol on one or less days a week, 0.81 (0.67 to 0.98 ) for 2-4 days a week, and 0.66 (0.52 to 0.83$)$ for 5 -7 days a week ( $\mathrm{P}$ for trend $=0.0001)$. Within categories of drinking frequency, hazard ratios tended to be similar.

To examine the possibility that latent baseline symptoms of coronary heart disease such as angina pectoris might reduce the frequency of drinking alcohol, thereby biasing the results, we carried out analyses to compare the association between drinking frequency and coronary heart disease only including early cases-that is, cases that occurred within the first two years of follow-up ( $\mathrm{n}=200$ women and $\mathrm{n}=381$ men)-with the association including only later cases $(n=549$ women and $\mathrm{n}=902$ men). An inverse association was observed in both groups (data not shown). 
Table 1 Baseline characteristics of 28448 women and 25052 men participating in the Danish diet, cancer, and health study according-sex and frequency of drinking alcohol. Values are medians (5th-95th centiles) unless stated otherwise

\begin{tabular}{|c|c|c|c|c|c|c|}
\hline \multirow{2}{*}{ Characteristic } & \multicolumn{6}{|c|}{ Frequency of drinking alcohol (days/week) } \\
\hline & Never & $<1$ & 1 & $2-4$ & 5 or 6 & 7 \\
\hline \multicolumn{7}{|l|}{ Women: } \\
\hline Number & 613 & 7160 & 4320 & 9373 & 3117 & 3865 \\
\hline Median (range) age (years) & $57(50-64)$ & $56(50-64)$ & $56(50-64)$ & $55(50-63)$ & $55(50-64)$ & $56(50-64)$ \\
\hline Alcohol intake (drinks/week) & $0(0)$ & $1(0.2-5)$ & $3.5(1.1-9)$ & $6.6(3-19)$ & $12.7(5.9-27)$ & $19.1(7.3-40)$ \\
\hline No (\%) current smokers & $252(41.1)$ & $2556(35.7)$ & $1266(29.3)$ & $2531(27.0)$ & $963(30.9)$ & $1650(42.7)$ \\
\hline $\begin{array}{l}\text { No }(\%) \text { current heavy } \\
\text { smokers* }\end{array}$ & $78(12.7)$ & $508(7.1)$ & $251(5.8)$ & $600(6.4)$ & $256(8.2)$ & $502(13.0)$ \\
\hline $\begin{array}{l}\text { No (\%) educated at school } \leq 7 \\
\text { years }\end{array}$ & $267(43.6)$ & $3072(42.9)$ & $1481(34.3)$ & $2456(26.2)$ & $598(19.2)$ & $877(22.7)$ \\
\hline Physical activity (hours/week) $\dagger$ & $14(4-41)$ & $15(5-40)$ & $15(5-38)$ & $15(6-35)$ & $15(6-34)$ & $15(5-38)$ \\
\hline Body mass index & $25.3(19-38)$ & $25.7(20-36)$ & $25.3(20-34)$ & $24.6(20-32)$ & $24.1(20-32)$ & $23.8(19-32)$ \\
\hline Vegetable intake (g/day) & $146(26-445)$ & $157(44-403)$ & $169(50-398)$ & $178(59-380)$ & 186 (65-389) & $172(51-378)$ \\
\hline Fruit intake (g/day) & $188(18-644)$ & 207 (36-609) & $213(42-565)$ & $202(44-547)$ & $195(38-531)$ & $167(27-492)$ \\
\hline Fish intake (g/day) & $30(3-84)$ & $32(9-85)$ & $36(11-85)$ & $37(13-83)$ & $37(13-83)$ & $37(11-86)$ \\
\hline $\begin{array}{l}\text { Saturated fat ( } \% \text { of total } \\
\text { energy) }\end{array}$ & $13(8-19)$ & $13(8-18)$ & $13(8-17)$ & $12(8-17)$ & $12(8-16)$ & $12(8-16)$ \\
\hline \multicolumn{7}{|l|}{ Men: } \\
\hline Number & 390 & 2464 & 2282 & 8718 & 4300 & 6898 \\
\hline Median (range) age (years) & $56(50-64)$ & $56(50-64)$ & $56(50-64)$ & $55(50-63)$ & $55(50-63)$ & $56(50-64)$ \\
\hline Alcohol intake (drinks/week) & $0(0-0)$ & $1.6(0.3-8)$ & $4.5(1.3-13)$ & $8.9(3.7-25)$ & $18.7(7-42)$ & $26.3(9.5-60)$ \\
\hline No (\%) current smokers & $192(49.2)$ & $1089(44.2)$ & $806(35.3)$ & $2973(34.1)$ & $1518(35.3)$ & $3249(47.1)$ \\
\hline $\begin{array}{l}\text { No }(\%) \text { current heavy } \\
\text { smokers* }\end{array}$ & $171(43.8)$ & $690(28.0)$ & $534(23.4)$ & $2171(24.9)$ & $1204(28.0)$ & $2407(34.9)$ \\
\hline $\begin{array}{l}\text { No }(\%) \text { educated at school } \leq 7 \\
\text { years }\end{array}$ & $154(39.5)$ & $1175(47.7)$ & $895(39.2)$ & $2851(32.7)$ & $1213(28.2)$ & 2228 \\
\hline Physical activity (hours/week) $\dagger$ & $12(2-39)$ & $11(3-33)$ & $11(3-30)$ & $11(4-29)$ & $11(4-29)$ & $11(4-31)$ \\
\hline Body mass index & $25.9(21-33)$ & $26.5(22-34)$ & $26.3(21-33)$ & $26.1(22-33)$ & $26.1(22-32)$ & $26.0(21-33)$ \\
\hline Vegetable intake (g/day) & 136 (25-393) & $130(38-335)$ & $145(47-343)$ & $157(53-341)$ & $162(55-340)$ & $149(44-336)$ \\
\hline Fruit intake (g/day) & $149(14-589)$ & $148(20-519)$ & $154(28-505)$ & $149(27-471)$ & $139(24-436)$ & $121(16-415)$ \\
\hline Fish intake (g/day) & $34(2-106)$ & $36(7-98)$ & $39(11-96)$ & $42(14-96)$ & $43(14-97)$ & $43(13-100)$ \\
\hline Saturated fat $(\%$ of total & $15(9-19)$ & $14(9-18)$ & $14(9-18)$ & $13(9-17)$ & $13(9-16)$ & $12(8-16)$ \\
\hline
\end{tabular}

${ }^{*}$ Smoking more than $25 \mathrm{~g}$ of tobacco daily.

†Sum of recreational and household activities.

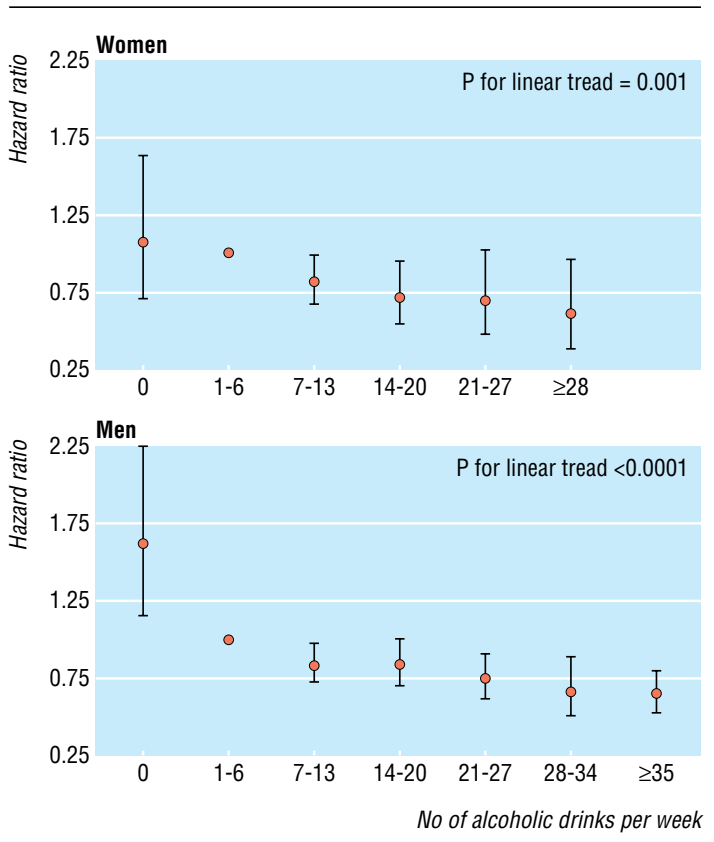

Hazard ratios (95\% confidence intervals), adjusted for age, smoking, education, physical activity, body mass index, and total intake of fruit, vegetables, fish, and saturated fat, for coronary heart disease according to alcohol intake among women and men. Abstainers were not included in analyses for trend

\section{Discussion}

The frequency of drinking alcohol is inversely associated with risk of coronary heart disease among men and this was independent of alcohol intake. Among women, alcohol intake and not drinking frequency was inversely associated with coronary heart disease.

A limitation of our study is that only $35 \%$ of the invited people participated and hence caution should be taken when generalising our findings. People who choose to participate may have a different risk profile and be in better health than those who decline. However, the observed incidence of coronary heart disease did not differ from that of the general population.

We found that the association between drinking frequency and coronary heart disease was different for men and women. The number of cases was substantially lower among women than among men, however, and hence results for women are less certain and warrant further study.

We cannot exclude the possibility that participants with early symptoms of coronary heart disease at baseline had reduced their drinking frequency, explaining the inverse association. However, this association persisted when we analysed early cases separately, indicating that the observed association is unlikely to be explained by this possible bias.

Some unhealthy traits (smoking and a low intake of fruit and vegetables) were common at both extremes of drinking frequency. Everyday drinking may be associated with borderline addictive behaviour, and a strong association between smoking 
Table 2 Hazard ratios (95\% confidence intervals) of coronary heart disease according to drinking frequency among women and men

\begin{tabular}{|c|c|c|c|c|c|c|c|c|c|}
\hline \multirow{2}{*}{ Variable } & \multicolumn{8}{|c|}{ Frequency of drinking alcohol (days/week) } & \multirow{2}{*}{$P$ for trend ${ }^{*}$} \\
\hline & Never & $<1$ & 1 & & $2-4$ & & 5 or 6 & 7 & \\
\hline \multicolumn{10}{|l|}{ Women: } \\
\hline No of cases & 24 & 276 & 95 & & 187 & & 77 & 90 & \\
\hline Adjusted for age & 1.01 (0.66 to 1.53$)$ & 1.00 & 0.60 (0.47 to 0.76$)$ & 0.56 & (0.47 to 0.68$)$ & 0.69 & (0.54 to 0.89 ) & 0.62 (0.49 to 0.79$)$ & 0.0004 \\
\hline $\begin{array}{l}\text { Adjusted for multiple } \\
\text { factors } \dagger\end{array}$ & 0.92 (0.61 to 1.41$)$ & 1.00 & 0.64 (0.51 to 0.81$)$ & 0.63 & (0.52 to 0.77 ) & 0.79 & (0.61 to 1.03 ) & 0.65 (0.51 to 0.84$)$ & $0.007 \ddagger$ \\
\hline \multicolumn{10}{|l|}{ Men: } \\
\hline No of cases & 39 & 180 & 140 & & 424 & & 195 & 305 & \\
\hline Adjusted for age & 1.38 (0.98 to 1.95) & 1.00 & 0.86 (0.69 to 1.07$)$ & 0.69 & (0.58 to 0.83$)$ & 0.65 & (0.53 to 0.79 ) & 0.60 (0.50 to 0.73$)$ & $<0.0001$ \\
\hline $\begin{array}{l}\text { Adjusted for multiple } \\
\text { factors } \dagger\end{array}$ & 1.44 (1.02 to 2.04$)$ & 1.00 & $0.93(0.75$ to 1.16$)$ & 0.78 & (0.66 to 0.94 ) & 0.71 & (0.57 to 0.87 ) & 0.59 (0.48 to 0.71$)$ & $<0.0001$ \\
\hline
\end{tabular}

*Never drinkers not included in analyses for trend.

†Age, smoking, education, physical activity, body mass index, total intake of fruit, vegetables, fish, and saturated fat.

tP for trend was 0.49 when women were excluded who never drink or drink on less than one day a week.

and drinking has been observed in many studies. ${ }^{15}$ For the most rare drinkers, the unhealthy lifestyle may be explained by the fact that they were the poorest educated, which probably correlates with low social status. Also this category may include former alcoholics. Together, results for the extremes of drinking frequency are more likely to be residually confounded than results for the in between drinking frequencies and should be interpreted with caution. However, at least among men, we found an inverse association between drinking frequency and coronary heart disease over the entire range of drinking frequencies.

Drinking patterns in our study were constructed by combining information on average intake with drinking frequency, as done in another study. ${ }^{6}$ We have avoided the term "binge drinking," which is mostly defined as drinking a minimum number of drinks per occasion and we cannot comment on this with the present data.

Several explanations may account for a possible interaction between sex and drinking frequency. One explanation is sex specific drinking habits, such as drinking with meals. We cannot exclude that men who drink frequently are more likely to drink with meals, which may contribute to a greater risk reduction compared with men with a less frequent alcohol intake. The beneficial effect of meal related alcohol intake is, however, controversial. ${ }^{6}$ It is unlikely that wine drinking, which may be more beneficial than drinking beer or spirits, ${ }^{16}$ is responsible for our results because it has been shown that wine drinkers in this cohort drink less often than beer drinkers. ${ }^{17}$ Differences in alcohol pharmacokinetics between sexes may be another explanation.?
The association between alcohol and coronary heart disease among women may be modified by menopausal status. Oestrogens have beneficial effects on the cardiovascular system, protecting women until menopause, when the incidence rapidly approaches that among men. ${ }^{18}$ Moderate alcohol drinking is thought to increase oestrogen levels. ${ }^{8}$ Few women in this study $(17 \%)$ were premenopausal and our findings may be limited to postmenopausal women.

The inverse association between alcohol and coronary heart disease can be explained by several biologically plausible mechanisms, including dose dependent effects on high density lipoprotein levels, lower plasma fibrinogen levels, and reduced platelet aggregation. ${ }^{19}$ These potential beneficial effects of alcohol must be considered along with potential adverse effects of a high intake, such as high blood pressure and increased triglyceride levels. ${ }^{20}$ The question is if the balance between beneficial and harmful effects is affected by drinking pattern. Heavy weekend drinkers have been found to have a higher daily blood pressure ${ }^{21}$ and to have greater between day variability in blood pressure than heavy daily drinkers. ${ }^{22}{ }^{23}$ Results are conflicting as to whether drinking pattern modifies lipid levels. Some studies found that only regular drinking can raise high density lipoprotein levels, ${ }^{24}{ }^{25}$ whereas others found this among weekend drinkers. ${ }^{26}$ The presumed lowering effect of alcohol on fibrinogen levels has been found to be independent of drinking pattern (daily versus weekend drinking). ${ }^{27}$ It has not been investigated if drinking pattern affects the presumed association between alcohol and increased oestrogen levels among women.

Table 3 Hazard ratios (95\% confidence intervals) of coronary heart disease according to drinking frequency and amount of alcohol intake among women and men

\begin{tabular}{|c|c|c|c|c|c|}
\hline \multirow{2}{*}{$\begin{array}{l}\text { Alcohol intake } \\
\text { (drinks/week) }\end{array}$} & \multicolumn{4}{|c|}{ Frequency of drinking alcohol (days/week) } & \multirow{2}{*}{$P$ for trend } \\
\hline & Never & $\leq 1$ & $2-4$ & $5-7$ & \\
\hline \multicolumn{6}{|l|}{ Women: } \\
\hline 0 & $1.03(0.68$ to 1.56$)(n=24)$ & - & - & - & - \\
\hline $1-6$ & - & $1.00(n=360)$ & 0.78 (0.63 to 0.97$)(n=114)$ & $1.32(0.84$ to 2.07$)(n=20)$ & 0.57 \\
\hline $7-13$ & - & 0.67 (0.35 to 1.31) $(n=9)$ & $0.74(0.57$ to 0.96$)(n=66)$ & $0.82(0.61$ to 1.10$)(n=52)$ & 0.12 \\
\hline$\geq 14$ & - & $0.65(0.16$ to 2.61$)(n=2)$ & $0.27(0.13$ to 0.58$)(n=7)$ & $0.72(0.57$ to 0.92$)(n=95)$ & 0.01 \\
\hline $\mathrm{P}$ for trend & - & 0.002 & $<0.0001$ & 0.0003 & - \\
\hline \multicolumn{6}{|l|}{ Men: } \\
\hline 0 & $1.47(1.05$ to 2.06$)(n=39)$ & - & - & - & \\
\hline $1-6$ & - & $1.00(n=278)$ & $0.80(0.65$ to 0.98$)(n=141)$ & $0.70(0.41$ to 1.17$)(n=15)$ & 0.02 \\
\hline $7-13$ & - & $0.89(0.62$ to 1.29$)(n=31)$ & $0.81(0.67$ to 0.98$)(n=190)$ & $0.66(0.52$ to 0.83$)(\mathrm{n}=90)$ & 0.0001 \\
\hline 14-20 & - & 1.10 (0.54 to 2.23) (n=8) & $0.91(0.68$ to 1.23$)(n=52)$ & $0.68(0.54$ to 0.87$)(n=90)$ & 0.001 \\
\hline$\geq 21$ & - & 1.00 (0.32 to 3.13$)(n=3)$ & $0.67(0.48$ to 0.93$)(n=41)$ & $0.63(0.53$ to 0.74$)(n=305)$ & $<0.0001$ \\
\hline$P$ for trend & - & 0.25 & 0.22 & $<0.0001$ & - \\
\hline
\end{tabular}

Hazard ratios are adjusted for age, education, smoking, physical activity, body mass index, and total intake of vegetables, fruit, fish, and saturated fat. Number of cases in parentheses. 
Heavy alcohol drinking is positively associated with many problems such as liver diseases, cancers, and road crashes, and overall mortality is higher among individuals with a high alcohol intake compared with light consumers, reflecting that the beneficial effects of alcohol on coronary heart disease is by far exceeded by the detrimental effects of alcohol at these levels. Also, the beneficial effect of alcohol is probably confined to middle aged or older people. ${ }^{28}$ Therefore the inverse association between alcohol intake and coronary heart disease should be viewed in this context when giving public health advice. In conclusion, we found that drinking frequency seemed to be the main determinant of the inverse association between alcohol intake and coronary heart disease among men, which confirms results from another study. ${ }^{6}$ For women, amount of alcohol may be more important than frequency.

We thank the participants of the diet, cancer, and health study.

Contributors: JT contributed to the conception and design of the study, the analysis and interpretation of data, and wrote the manuscript. MKJ, KJM, and MG contributed to the conception and design of the study, interpretation of data, and to critically revising the paper. AT and KO contributed to the design of the study, the acquisition of data, interpretation of data, and critically revising the paper. All authors approved the final version of the article. Katja Boll prepared the data file and Søren Rasmussen calculated incidence rates of coronary heart disease in the general Danish population. $\mathrm{MG}$ is the guarantor.

Funding: This study was supported by grants from the Health Insurance Foundation, the Ministry of the Interior and Health, the Danish Cancer Society, and the Danish National Board of Health.

Competing interests: None declared.

Ethical approval: This study was approved by the ethical committees for the Copenhagen and Aarhus municipalities (KF 01-116/96).

1 Flesch M, Rosenkranz S, Erdmann E, Bohm M. Alcohol and the risk of myocardial infarction. Basic Res Cardiol 2001;96:128-35.

2 Malyutina S, Bobak M, Kurilovitch S, Gafarov V, Simonova G, Nikitin Y, et al. Relation between heavy and binge drinking and all-cause and cardiovascular mortality in Novosibirsk, Russia: a prospective cohort study. Lancet 2002;360:1448-54

3 McElduff P, Dobson AJ. How much alcohol and how often? Population based case-control study of alcohol consumption and risk of a major coronary event. BMJ 1997;314:1159-64.

4 Trevisan M, Dorn J, Falkner K, Russell M, Ram M, Muti P, et al. Drinking pattern and risk of non-fatal myocardial infarction: a population-based case-control study. Addiction 2004;99:313-22.

\section{What is already known on this topic}

Alcohol intake is inversely associated with risk of coronary heart disease

In men, for the same weekly amount of alcohol intake, frequent drinkers have a lower risk of coronary heart disease than less frequent drinkers

Little is known about drinking pattern and the risk of coronary heart disease among women

\section{What this study adds}

Intake may be more important than frequency for the inverse association between alcohol drinking and risk of coronary heart disease among women

In men, frequency is more important than alcohol intake
5 Murray RP, Connett JE, Tyas SL, Bond R, Ekuma O, Silversides CK, et al. Alcohol volume, drinking pattern, and cardiovascular disease morbidity and mortality: is there a U-shaped function? Am J Epidemiol 2002;155:242-8.

6 Mukamal KJ, Conigrave KM, Mittleman MA, Camargo CA Jr, Stampfer MJ, Willett WC, et al. Roles of drinking pattern and type of alcohol consumed in coronary heart disease in men. N Engl J Med 2003;348:109-18.

7 Mumenthaler MS, Taylor JL, O'Hara R, Yesavage JA. Gender differences in moderate drinking effects. Alcohol Res Health 1999;23:55-64.

8 Register TC, Cline JM, Shively CA. Health issues in postmenopausal women who drink. Alcohol Res Health 2002;26:299-307.

9 Tjonneland A, Gronbaek M, Stripp C, Overvad K. Wine intake and diet in a random sample of 48763 Danish men and women. Am J Clin Nutr 1999;69:49-54.

10 Overvad K, Tjonneland A, Haraldsdottir J, Ewertz M, Jensen OM. Development of a semiquantitative food frequency questionnaire to assess food, energy and nutrient intake in Denmark. Int J Epidemiol 1991;20:900-5.

11 Tjonneland A, Overvad K, Haraldsdottir J, Bang S, Ewertz M, Jensen OM. Validation of a semiquantitative food frequency questionnaire developed in Denmark. Int J Epidemiol 1991;20:906-12.

12 Jürgensen HJ, Frølund C, Gustafsen J, Mosbech H, Guldhammer B, Mosbech J. Registration of diagnoses in the Danish National Registry of patients. Methods Inform Med 1986;25:158-64.

13 Juel K, Helweg-Larsen K. The Danish registers of causes of death. Dan Med Bull 1999;46:354-7.

14 Shaper AG. Mortality and alcohol consumption. Non-drinkers shouldn't be used as baseline. BMJ 1995;310:325.

15 Bien TH, Burge R. Smoking and drinking: a review of the literature. Int J Addict 1990;25:1429-54.

16 Gronbaek M, Becker U, Johansen D, Gottschau A, Schnohr P, Hein HO, et al. Type of alcohol consumed and mortality from all causes, coronary heart disease, and cancer. Ann Intern Med 2000;133:411-9.

17 Gronbaek M, Tjonneland A, Johansen D, Stripp C, Overvad K. Type of alcohol and drinking pattern in 56,970 Danish men and women. Eur J Clin Nutr 2000;54:174-6.

18 Colditz GA, Willett WC, Stampfer MJ, Rosner B, Speizer FE, Hennekens CH. Menopause and the risk of coronary heart disease in women. $N$ Engl J Med 1987;316:1105-10.

19 Agarwal DP. Cardioprotective effects of light-moderate consumption of alcohol: a review of putative mechanisms. Alcohol Alcohol 2002;37:409-15.

20 Puddey IB, Rakic V, Dimmitt SB, Beilin LJ. Influence of pattern of drinking on cardiovascular disease and cardiovascular risk factors-a review. Addiction 1999;94:649-63.

21 Wannamethee G, Shaper AG. Alcohol intake and variations in blood pressure by day of examination. J Hum Hypertens 1991;5:59-67.

22 Marmot MG, Elliott P, Shipley MJ, Dyer AR, Ueshima H, Beevers DG, et al. Alcohol and blood pressure: the INTERSALT study. BMJ 1994;308:1263-7.

23 Rakic V, Puddey IB, Burke V, Dimmitt SB, Beilin LJ. Influence of pattern of alcohol intake on blood pressure in regular drinkers: a controlled trial. J Hypertens 1998:16:165-74.

24 Gruchow HW, Hoffmann RG, Anderson AJ, Barboriak JJ. Effects of drinking patterns on the relationship between alcohol and coronary occlusion. Atherosclerosis 1982;43:393-404.

25 Hojnacki JL, Deschenes RN, Cluette-Brown JE, Mulligan JJ, Osmolski TV, Rencricca NJ, et al. Effect of drinking pattern on plasma lipoproteins and body weight. Atherosclerosis 1991;88:49-59.

26 Rakic V, Puddey IB, Dimmitt SB, Burke V, Beilin LJ. A controlled trial of the effects of pattern of alcohol intake on serum lipid levels in regular drinkers. Atherosclerosis 1998:137:243-52.

27 Dimmitt SB, Rakic V, Puddey IB, Baker R, Oostryck R, Adams MJ, et al. The effects of alcohol on coagulation and fibrinolytic factors: a controlled trial. Blood Coagul Fibrinolysis 1998;9:39-45.

28 Fuchs CS, Stampfer MJ, Colditz GA, Giovannucci EL, Manson JE, Kawachi I, et al. Alcohol consumption and mortality among women. N EnglJ Med 1995;332:1245-50.

(Accepted 7 March 2006)

doi 10.1136/bmj.38831.503113.7C

Centre for Alcohol Research, National Institute of Public Health, Øster Farimagsgade 5, Dk-1399 Copenhagen, Denmark

Janne Tolstrup research fellow

Majken K Jensen research fellow

Morten Grønbæk professor

Institute of Cancer Epidemiology, Danish Cancer Society, Copenhagen Anne Tjønneland senior research fellow

Department of Clinical Epidemiology, Cardiovascular Research Center, Aarhus University Hospital, Aalborg

Kim Overvad research director

Division of General Medicine and Primary Care, Beth Israel Deaconess Medical Center, Boston, USA

Kenneth J Mukamal assistant professor

Correspondence to: J Tolstrup jst@niph.dk 